\title{
Australia Establishes Materials Science Committee
}

Materials research in Australia covers a wide spectrum of interests and involves many general and specialized scientific societies. Until recently there has been relatively little in the way of coordinated activity, but the establishment of the Australian Materials Science Committee as an Adhering Body of the International Union of Materials Research Societies is a first step toward remedying this situation.

Australian science is unusual on the world scene because of the key role played by the Commonwealth Scientific and Industrial Research Organization, CSIRO, which has a staff of about 3,000 professional scientists and a total staff of 7,000 . CSIRO activities cover the entire spectrum of science, except for medicine and nuclear science, and several laboratories are extensively involved in materials fields. Other government laboratories, particularly those of the Australian Nuclear Science and Technology Organization (ANSTO) and those of the Defense Science and Technology Organization (DSTO) similarly have major involvement in materials for their own more specific purposes. Universities play their usual important role in both teaching and research, supported by grants from the Australian Research Coun- cil, and many have significant programs in materials-related areas.

Industrial research in Australia falls short of matching that in the governmentsupported sector, and this is a source of general concern. Within the materials area, however, there are major industrial laboratories associated with the largest Australian producers of steel, aluminum, and related materials.

Materials-related activities are the focus of groups within several of the major scientific societies, notably the Institution of Engineers (including the Institute of Mining and Metallurgy), the Australian Institute of Physics, the Royal Australian Chemical Institute, the Australian Ceramics Society, and several specialized societies dealing with $\mathrm{x}$-ray diffraction, electron microscopy, and related instrumental techniques. Many of these societies hold annual conferences in which materials topics play a large part, and for the past 20 years the Australian Institute of Physics has held a well-attended annual conference on solidstate physics, which is now expanding to embrace other more applied aspects of materials science.

The role of the new Committee, whose membership will consist of nominees of appropriate scientific and engineering societies, industry associations, and relevant government departments or agencies, is seen to be essentially one of exchanging information and coordinating activities between complementary groups in the materials community. There is no thought of constituting a stand-alone materials society in competition with the programs of existing societies. An additional important task of the new Committee will be to strengthen links between those working with materials in industry and those whose concerns are more with advances on the research front.

Initial meetings of representatives of potential member societies have been held, and it seems that the new committee will receive an enthusiastic launching before the end of the year.

For more information about the Australian Materials Science Committee, contact: J.S. Williams or Robert G. Elliman, Department of Electronic Materials Engineering, Research School of Physical Sciences and Engineering, Australian National University, GPO Box 4, Canberra, ACT, 2601, Australia, phone 61-6-249-0020, fax 61-6249-0511.

\section{First International Conference on Nanostructured Materials}

September 21 - 25, 1992 - Cancun, Mexico

Organized by: Academia Mexicana de Ciencia de Materiales and Acta Metallurgica

This conference is designed to promote a worldwide exchange of information among researchers in the field of nanostructured materials. Oral and poster presentations are being solicited on the following topics:

Cluster and cluster-assembled materials;

Structure and characterization of nanophases;

Synthesis and processing of nanostructured materials: physical, chemical, and biological methods;

Properties: mechanical, electrical, optical, rheological, magnetic, etc.;

Performance and applications: tribology, corrosion, etc.; and

Related fields such as nanolithography, nanodevices, etc.

Abstracts of 200-300 words are due to the conference secretariat before April 1, 1992.

Secretariat, First International Conference on Nanostructured Materials, Dr. Victor Castano, Instituto de Fisica, UNAM, Apartado postal 20-364, C.P. 01000 Mexico D.F., Mexico; phone 525-548-58-78; fax 525-548-31-11 